\title{
ASO Visual Abstract: Temporizing Wound VAC Dressing Until Final Negative Margins are Achieved Reduces Myxofibrosarcoma Local Recurrence
}

Mitchell S. Fourman, MD, MPhil ${ }^{1}$, Duncan C. Ramsey, MD, MPH ${ }^{1}$, Justin Kleiner, MD $^{2}$, Anser Daud, BS ${ }^{3}$, Erik T. Newman, MD ${ }^{1}$, Joseph H. Schwab, MD, MS ${ }^{1}$, Yen-Lin Chen, MD $^{4}$, Thomas F. DeLaney, $\mathrm{MD}^{4}$, John T. Mullen, $\mathrm{MD}^{5}$, Kevin A. Raskin, $\mathrm{MD}^{1}$, and Santiago Lozano-Calderon, MD, $\mathrm{PhD}^{1}$

${ }^{1}$ Department of Orthopaedic Surgery, Massachusetts General Hospital, Boston, MA ; ${ }^{2}$ Department of Orthopaedic Surgery, Boston Medical Center, Boston, MA; ${ }^{3}$ Faculty of Medicine, University of Toronto, Toronto, ON, Canada; ${ }^{4}$ Department of Radiation Oncology, Massachusetts General Hospital Cancer Center, Boston, MA; ${ }^{5}$ Department of Surgery, Massachusetts General Hospital, Boston, MA

Suprafascial myxofibrosarcoma is microinvasive, and negative margins often are unclear using intraoperative frozen sectioning alone. Temporizing the wound bed with a VAC pending final margin analysis significantly reduces the local recurrence rate of suprafascial myxofibrosarcoma from $28.6 \%$ to $5.6 \%$ (https://doi.org/10. 1245/s10434-021-10242-4).
Publisher's NoteSpringer Nature remains neutral with regard to jurisdictional claims in published maps and institutional affiliations.

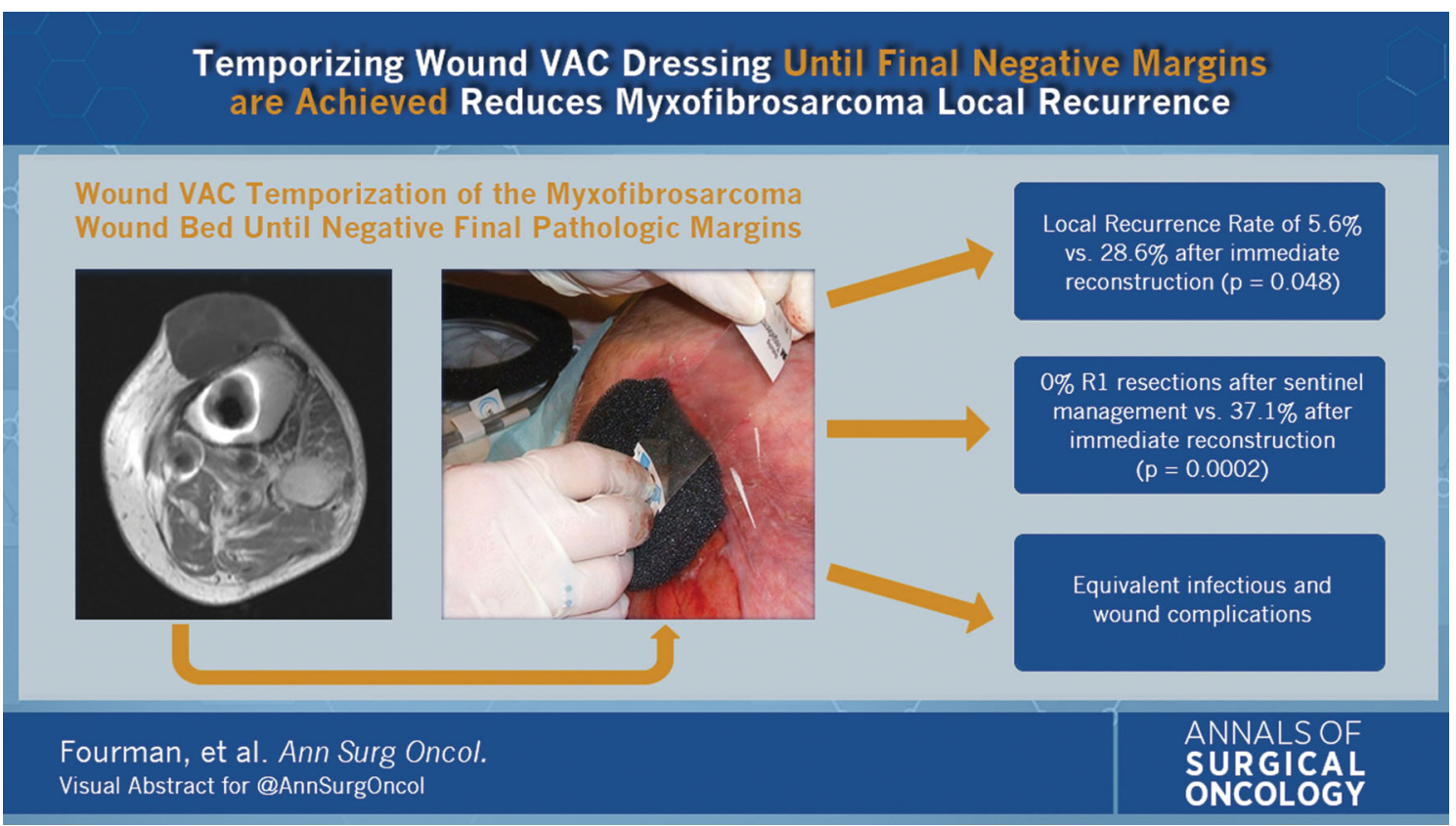

(C) Society of Surgical Oncology 2021

Published Online: 11 June 2021

S. Lozano-Calderon, MD, $\mathrm{PhD}$

e-mail: slozanocalderon@mgh.harvard.edu 